\title{
Rates of microbial hydrogen oxidation and sulfate reduction in Opalinus Clay rock
}

\author{
Alexandre Bagnoud ${ }^{\mathrm{a}, \mathrm{b}}$, Olivier Leupin ${ }^{\mathrm{c}}$, Bernhard Schwyn ${ }^{\mathrm{c}}$, Rizlan Bernier-Latmani ${ }^{\mathrm{a},{ }^{*}}$ \\ ${ }^{a}$ Environmental Microbiology Laboratory, EPFL, Station 6, Lausanne 1015, Switzerland \\ b Stream Biofilm and Ecology Research Laboratory, EPFL, Station 2, Lausanne 1015, Switzerland \\ ${ }^{\mathrm{c}}$ NAGRA, National Cooperative for the Disposal of Radioactive Waste, Hardstrasse 73, Wettingen 5430, Switzerland
}

\section{A R T I C L E I N F O}

\section{Article history:}

Received 29 February 2016

Received in revised form

25 June 2016

Accepted 28 June 2016

Available online 2 July 2016

\section{Keywords:}

Deep geological repository

Mt Terri Underground Rock Laboratory

Anoxic steel corrosion

Sulfate-reducing bacteria

Geomicrobiology

\begin{abstract}
A B S T R A C T
Hydrogen gas $\left(\mathrm{H}_{2}\right)$ may be produced by the anoxic corrosion of steel components in underground structures, such as geological repositories for radioactive waste. In such environments, hydrogen was shown to serve as an electron donor for autotrophic bacteria. High gas overpressures are to be avoided in radioactive waste repositories and, thus, microbial consumption of $\mathrm{H}_{2}$ is generally viewed as beneficial. However, to fully consider this biological process in models of repository evolution over time, it is crucial to determine the in situ rates of microbial hydrogen oxidation and sulfate reduction. These rates were estimated through two distinct in situ experiments, using several measurement and calculation methods. Volumetric consumption rates were calculated to be between 1.13 and $1.93 \mu \mathrm{mol} \mathrm{cm}^{-3} \mathrm{day}^{-1}$ for $\mathrm{H}_{2}$, and 0.14 and $0.20 \mu \mathrm{mol} \mathrm{cm}{ }^{-3}$ day $^{-1}$ for sulfate. Based on the stoichiometry of the reaction, there is an excess of $\mathrm{H}_{2}$ consumed, suggesting that it serves as an electron donor to reduce electron acceptors other than sulfate, and/or that some $\mathrm{H}_{2}$ is lost via diffusion. These rate estimates are critical to evaluate whether biological $\mathrm{H}_{2}$ consumption can negate $\mathrm{H}_{2}$ production in repositories, and to determine whether sulfate reduction can consume sulfate faster than it is replenished by diffusion, which could lead to methanogenic conditions.
\end{abstract}

() 2016 Elsevier Ltd. All rights reserved.

\section{Introduction}

Based on an international consensus, deep geological repositories are the preferred option for the disposal of radioactive waste (IAEA, 2003). An in-depth understanding of host rock processes relevant to safety is thus required, including the impact of microorganisms under repository relevant conditions. A few European countries have opted for a repository design that consists of waste sealed in carbon steel containers that are placed in a lowpermeability Clay rock formation (ANDRA, 2005; Nagra, 2002). Steel is expected to corrode under reducing conditions at a rate of a few micrometers a year, producing iron oxide minerals (e.g., magnetite) and gaseous hydrogen $\left(\mathrm{H}_{2}\right)$ (King, 2008; Marsh and Taylor, 1988). Another source of $\mathrm{H}_{2}$, but likely in lesser amounts, is the alpha-radiolysis of water after canister breaching (Le Caër, 2011). $\mathrm{H}_{2}$ is believed to build up at higher rates than can be dissipated via diffusion. In this case, a free gas phase can form and

\footnotetext{
* Corresponding author.

E-mail address: rizlan.bernier-latmani@epfl.ch (R. Bernier-Latmani).
}

migrate through the clay via two-phase flow or pathway dilation through the host-rock (Marschall et al., 2005). However, $\mathrm{H}_{2}$ is also known to be an excellent source of energy that can support microbial growth and activity (Nealson et al., 2005). Thus, the consumption of $\mathrm{H}_{2}$ by microbial activity could be beneficial to the longterm safety of the repository (Libert et al., 2011).

In Switzerland, Opalinus Clay, a clayey rock formation, is the current candidate to host a deep geological repository (Pearson et al., 2003). Results from an in-situ experiment on hydrogen diffusion through this rock formation that took place in the Mont Terri Underground laboratory, $300 \mathrm{~m}$ below the surface (Thury and Bossart, 1999), suggested that $\mathrm{H}_{2}$ is being consumed by biological processes as it disappeared 20 times faster than accounted for by abiotic processes (Vinsot et al., 2014). A separate in situ experiment, carried out in the same facility, clearly showed that $\mathrm{H}_{2}$ was oxidized microbiologically through a complex metabolic network (Bagnoud et al., submitted). Thus, it is expected that hydrogen gas might be utilized in a geological underground repository if the boundary conditions allow for it. The mechanism of hydrogen utilization in a repository have been discussed elsewhere (Nagra, in prep.) and are well established, but its rate of consumption remains uncertain. 


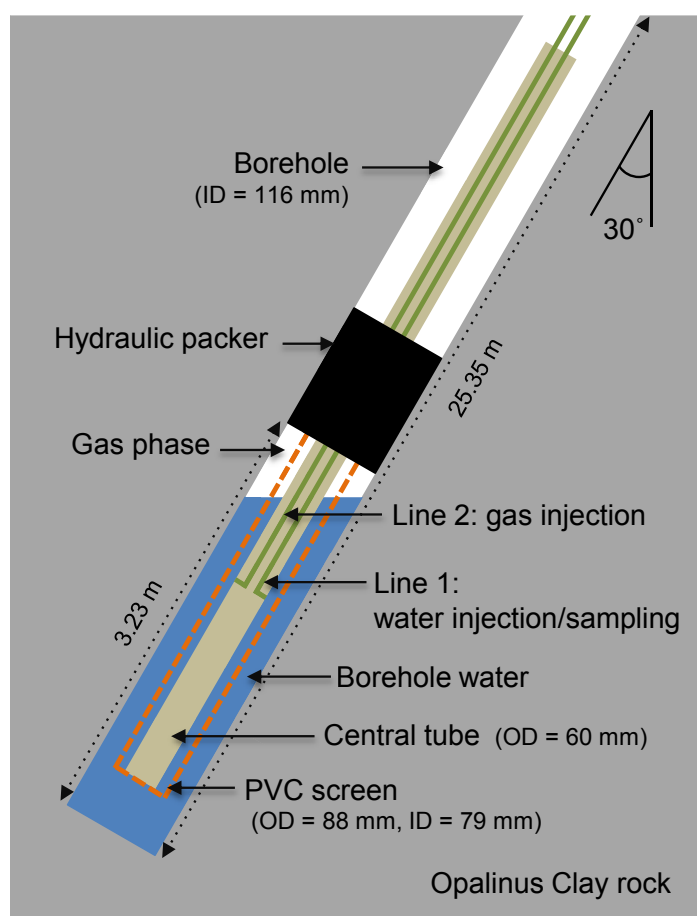

Fig. 1. Borehole equipment of BRC-3, which has an inclined descending orientation, forming a $30^{\circ}$ angle with the zenith. Downhole equipment includes a central tube containing sampling lines (line 1 for water sampling and injection; line 2 for gas injection), a hydraulic packer and a PVC screen. Not to scale.

Determination of the in situ kinetics of $\mathrm{H}_{2}$ oxidation is essential in order to complete the geochemical modeling of the repository and to account for biological contributions to $\mathrm{H}_{2}$ consumption.

Furthermore, the rate of sulfate $\left(\mathrm{SO}_{4}^{2-}\right)$ reduction is a key parameter in evaluating whether sulfate depletion via hydrogenfueled microbial sulfate reduction will exceed the influx of sulfate via diffusion from the rock. The depletion of sulfate, if it occurs, may enable the growth of methanogens. The establishment of a methanogenic microbial community would result in a lesser reduction of the gas pressure than sulfidogenic conditions due to the production of methane $\left(\mathrm{CH}_{4}\right)$, because the latter exhibits low solubility in water.

An experiment was carried out to characterize the microbial community that develops in response to $\mathrm{H}_{2}$ amendments into a borehole within the Opalinus Clay formation (Bagnoud et al., submitted). While assessing rates of $\mathrm{H}_{2}$ oxidation and sulfate reduction was not the primary goal of the experiment, it provided a unique opportunity to estimate these rates in situ. The collected data were evaluated using the differential rate $\left(\mathrm{H}_{2}, \mathrm{SO}_{4}^{2-}\right)$ of consumption per time unit. The dependence of the consumption rates on hydrogen and sulfate concentrations as well as on the biomass was not obtainable. Nevertheless, the present work utilizes the data gathered from the $\mathrm{H}_{2}$ amendment experiment to obtain a range of values for the rate of $\mathrm{H}_{2}$ and sulfate consumption that could be of use to others in the nuclear waste disposal community as well as the subsurface $\mathrm{H}_{2}$ storage community.

\section{Materials and methods}

\subsection{Experimental set-up}

The experimental set-up was described previously by Bagnoud et al. (Bagnoud et al., submitted). Briefly, an inclined descending borehole (borehole BRC-3) at the Mont-Terri Underground Rock Laboratory (URL), producing $20 \mathrm{~mL} /$ day of porewater (due to a pressure differential between the rock formation and the borehole of about 10 bars), was equipped with a hydraulic packer in order to preserve reducing conditions and to enable a hydraulic pressure buildup (Fig. 1). Polyamide lines were connected to the surface through a series of lines and valves (referred to as surface equipment). This surface equipment allowed for water recirculation using a peristaltic pump (at a flow rate of $5 \mathrm{~mL} / \mathrm{min}$ ), water and gas sampling through needle valves, and hydrogen gas injection using a gas reservoir connected to the water circuit by a gas permeable membrane. A schematic representing the timescale set-up of the $\mathrm{H}_{2}$ injection experiment is given in Fig. 2.

Bromide $\left(\mathrm{Br}^{-}\right)$was amended to the borehole water as a conservative tracer in an initial pulse, before the start of the experiment. Hydrogen gas was then supplied to the circulating porewater for over 500 days (with some interruptions; Fig. 2). During the first 139 days, this amendment was delivered continuously as a gas

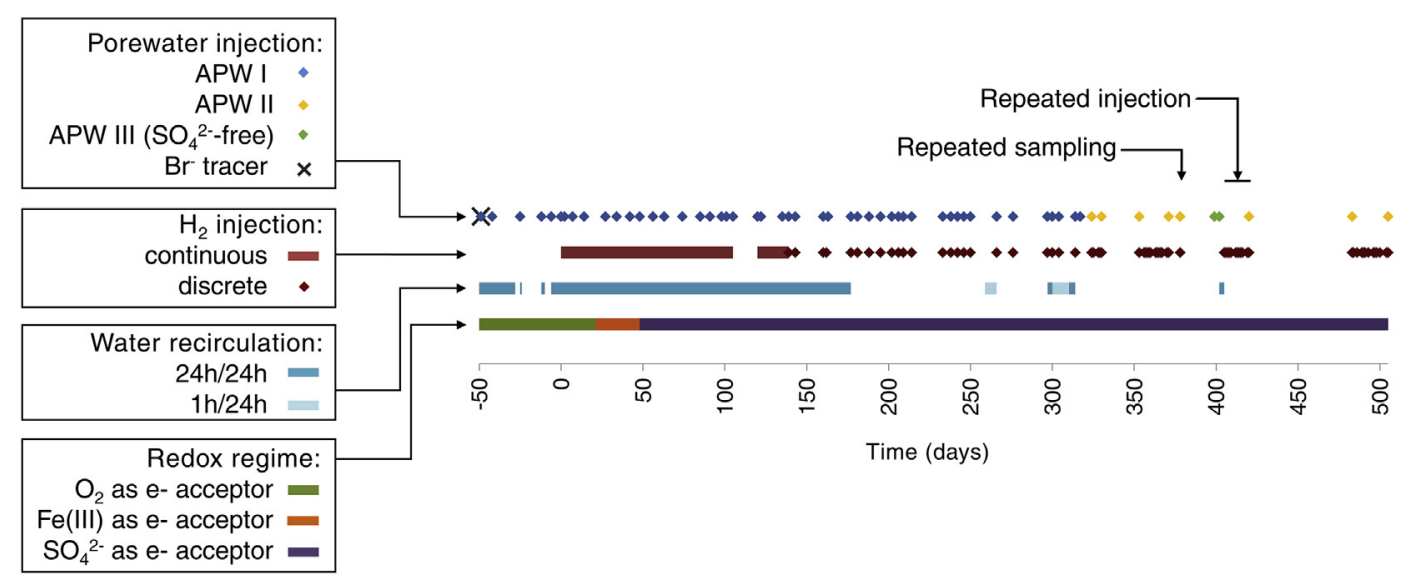

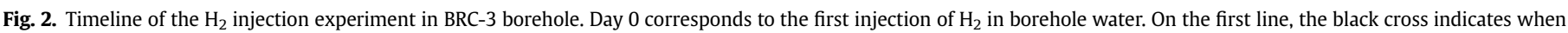

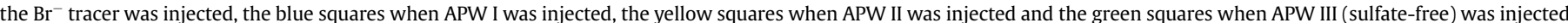

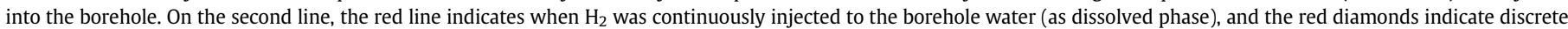

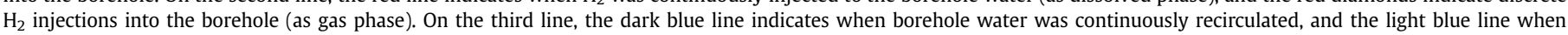

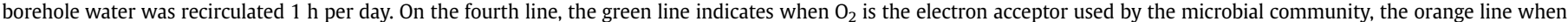

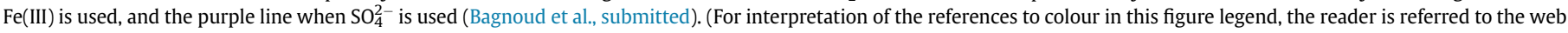
version of this article.) 
Table 1

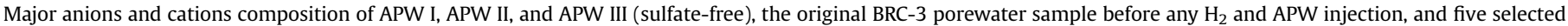
BRC-3 porewater samples after $\mathrm{H}_{2}$ injection.

\begin{tabular}{|c|c|c|c|c|c|c|c|c|c|c|}
\hline Sample & & $\begin{array}{l}\mathrm{Na}^{+} \\
(\mathrm{mM})\end{array}$ & $\begin{array}{l}\mathrm{Mg}^{2+} \\
(\mathrm{mM})\end{array}$ & $\begin{array}{l}\mathrm{K}^{+} \\
(\mathrm{mM})\end{array}$ & $\begin{array}{l}\mathrm{Ca}^{2+} \\
(\mathrm{mM})\end{array}$ & $\begin{array}{l}\mathrm{Cl}^{-} \\
(\mathrm{mM})\end{array}$ & $\begin{array}{l}\mathrm{SO}_{4}^{2-} \\
(\mathrm{mM})\end{array}$ & $\begin{array}{l}\mathrm{HCO}_{3}^{-} \\
(\mathrm{mM})\end{array}$ & $\begin{array}{l}\mathrm{Br}^{-} \\
(\mathrm{mM})\end{array}$ & $\begin{array}{l}\mathrm{S}(-\mathrm{II}) \\
(\mu \mathrm{M})\end{array}$ \\
\hline \multirow{3}{*}{$\begin{array}{l}\text { Artificial porewater (theoretical } \\
\text { concentrations) }\end{array}$} & APW I & 255.59 & 17.89 & 1.46 & 15.79 & 294.58 & 14.70 & 0.57 & 0.00 & 0 \\
\hline & APW II & 270.00 & 23.02 & 2.12 & 18.88 & 307.76 & 23.83 & 0.57 & 0.00 & 0 \\
\hline & $\begin{array}{l}\text { APW III (sulfate- } \\
\text { free) }\end{array}$ & 222.34 & 23.02 & 2.12 & 18.88 & 307.76 & 0.00 & 0.57 & 0.00 & 0 \\
\hline \multicolumn{2}{|c|}{ Initial BRC-3 borehole water (before $\mathrm{H}_{2}$ or APW injection) } & 329.46 & 26.32 & 2.43 & 21.51 & 288.84 & 25.37 & n. d. & 0.00 & n. d. \\
\hline \multirow[t]{5}{*}{ BRC-3 borehole water (after $\mathrm{H}_{2}$ was injected) } & at day 0 & 320.14 & 23.25 & 2.15 & 18.79 & 299.69 & 17.88 & n. d. & 10.12 & 0 \\
\hline & at day 101 & 285.31 & 22.70 & 1.05 & 16.53 & 311.02 & 16.58 & n. d. & 3.65 & 5 \\
\hline & at day 238 & 269.69 & 10.08 & 0.48 & 15.22 & 273.41 & 12.93 & n. d. & 1.26 & n. d. \\
\hline & at day 304 & 239.59 & 16.41 & 0.56 & 16.11 & 258.20 & 14.61 & n. d. & 1.20 & 103 \\
\hline & at day 420 & n. d. & n. d. & n. d. & n. d. & 317.10 & 5.88 & n. d. & 0.63 & 606 \\
\hline
\end{tabular}

'n. d.' stands for 'not determined'.

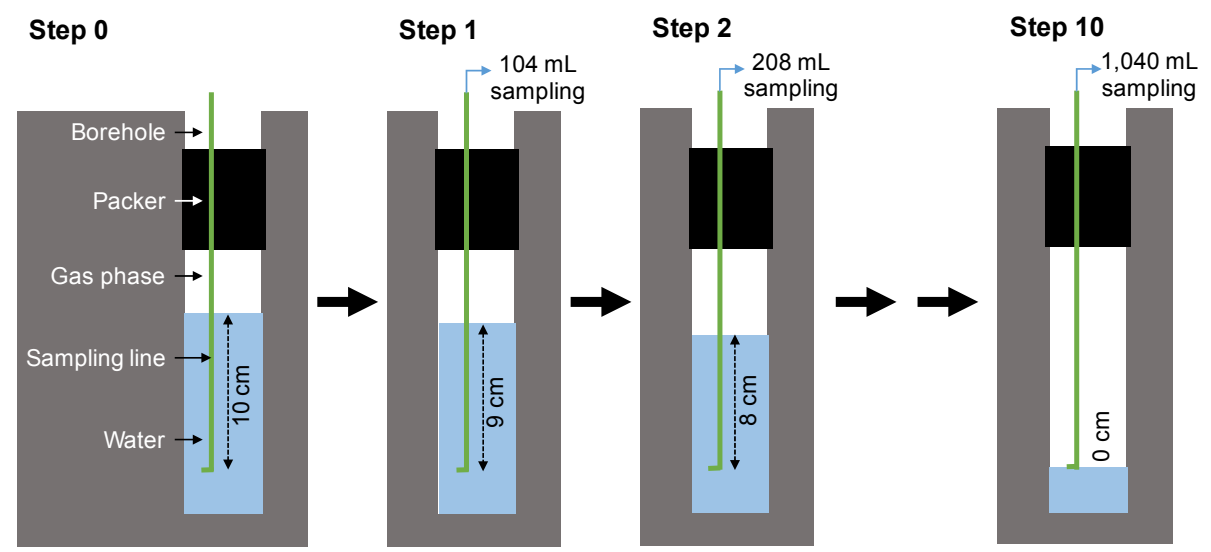

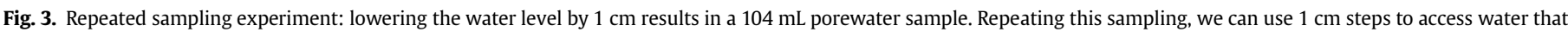

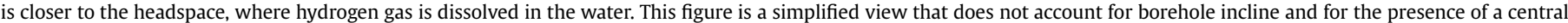
tube and a screen, as shown in Fig. 1.

phase via the gas permeable membrane, except between days 105 and 120. Later, hydrogen was directly injected into the borehole, creating a gas cushion below the hydraulic packer. Water circulation was discontinued starting at day 178 . Approximately once a week, water (between 400 and $1000 \mathrm{~mL}$ ) was sampled and replaced by artificial porewater (APW). APW I was the replacement solution until day 324, after which APW II was used. The latter was based on the chemical composition of the first BRC-3 water samples, withdrawn before any $\mathrm{H}_{2}$ amendment or APW injection. APW III (sulfate-free) was injected at days 399 and 402 (Table 1; Fig. 2). These large sample volumes were collected for molecular analysis of the microbial community, which is presented in a separate publication (Bagnoud et al., submitted), but a small volume was also preserved from each sample to quantify major anion and cation concentrations.

\subsection{Experimental procedures}

During the 500 days of hydrogen gas injection, three experiments were carried out to evaluate the in situ rates of hydrogen oxidation and of sulfate reduction.

The first experiment (repeated sampling) was carried out by repeated samplings of the borehole on day 378 , one week after the last APW I injection, and $24 \mathrm{~h}$ after the last injection of $1 \mathrm{~L}$ of hydrogen gas. This injection increased the borehole pressure by 5.4 bars (compared to atmospheric pressure), which allowed borehole water to be collected simply by opening the sampling line. Because the water column is stratified, repeated sampling of a given volume is equivalent to collecting discrete samples as a function of depth. Indeed, for every $104 \mathrm{~mL}$ of borehole water sample, the water table is lowered by $1 \mathrm{~cm}$. This means that a sample will be $1 \mathrm{~cm}$ closer to the water table than the previous one, as depicted in Fig. 3. The water was then collected as $\sim 100 \mathrm{~mL}$ aliquots from the downhole sampling port (line 1), to investigate the changing porewater composition as a function of distance from the gas phase. All the $\sim 100 \mathrm{~mL}$ aliquots were filtered through a $0.2 \mu \mathrm{m}$ nylon filter, and analyzed for $\mathrm{SO}_{4}^{2-}$, sulfide $(\mathrm{S}(-\mathrm{II}))$ and dissolved $\mathrm{H}_{2}$. In total, 10 samples were collected before the gas phase reached the sampling line.

The second experiment (repeated injection) was conducted on day 405, 3 days after the injection of APW II and continuous recirculation of borehole porewater. The pump was shut down, and water collected using the borehole excess pressure. After discarding the dead volume in the lines, water was analyzed for $\mathrm{SO}_{4}^{2-}, \mathrm{Br}^{-}$, sulfide $(\mathrm{S}(-\mathrm{II}))$, dissolved $\mathrm{H}_{2}$ and $\delta^{34} \mathrm{~S}-\mathrm{SO}_{4} . \delta^{34} \mathrm{~S}$ is defined according to Eq. (1):

$$
\delta^{34} S=\left(\left(R_{\text {sample }}-R_{\text {reference }}\right) / R_{\text {reference }}\right) \cdot 1000 \%
$$

where $R={ }^{34} S /{ }^{32} \mathrm{~S}$. Immediately after sampling, $1 \mathrm{~L}$ of $\mathrm{H}_{2}$ gas was injected into the borehole, and a new sample collected to quantify the concentration of dissolved $\mathrm{H}_{2}$ resulting from this injection. The combination of water sampling, followed by hydrogen injection, and followed by another water sampling, was repeated 11 times within a period of 15 days.

The third experiment consisting of a laboratory incubation test 
intended to quantify $\mathrm{SO}_{4}^{2-}$ and $\mathrm{S}(-\mathrm{II})$ concentrations as well as $\delta^{34} \mathrm{~S}-\mathrm{SO}_{4}$ during an in vitro batch incubation of borehole water, under sulfate-reducing conditions. A volume of $950 \mathrm{~mL}$ of porewater was collected anoxically and under sterile conditions on day 314 and transferred in a 1-L bottle to which $1.5 \mathrm{~mL}$ of $150 \mathrm{mM}$ $\mathrm{KH}_{2} \mathrm{PO}_{4}(\mathrm{pH} 7.2)$ were amended to mimic the release of phosphate from the Opalinus Clay. The headspace of the bottle was flushed with $100 \% \mathrm{H}_{2}$ to a pressure of 0.85 relative bar. The bottle was then incubated at $17.5^{\circ} \mathrm{C}$ and sampled periodically over a period of 107 days (10 samples were collected).

\subsection{Chemical analyses}

For major cation and anion quantification, a sample of $2 \mathrm{~mL}$ of water was filtered using a $0.2 \mu \mathrm{m}$ nylon filter, and stored at $-20^{\circ} \mathrm{C}$ until analysis. Immediately before analysis, each sample was refiltered and diluted 10, 100, and 1000 times with MilliQ water. Samples were analyzed by ion chromatography (DX-3000, Dionex, Sunnyvale, USA) with an IonPac CS16 Cation-Exchange column and $40 \mathrm{mM}$ of methanesulfonic acid for elution, to measure major cations, and with an IonPac AS11-HC column and $\mathrm{KOH}$ gradient from 0.5 to $30 \mathrm{mM}$ for the elution, to measure major anions. Analytical error (1-sigma error) is less than $4 \%$.

$\delta^{34} \mathrm{~S}-\mathrm{SO}_{4}$ was measured on water samples filtered through $0.2 \mu \mathrm{m}$ nylon filters. Prior to analysis, S(-II) was removed by reaction with zinc acetate at a concentration of $1 \%(\mathrm{w} / \mathrm{v})$ and incubation for $2 \mathrm{~h}$ at room temperature. Subsequently, the solution was centrifuged at $4500 \times \mathrm{g}$ for $10 \mathrm{~min}$ and the pellet discarded. Measurement of $\delta^{34} \mathrm{~S}-\mathrm{SO}_{4}$ was carried out by Hydroisotop (Schweitenkirchen, Germany). Briefly, $\mathrm{BaSO}_{4}$ was precipitated by the addition of $\mathrm{BaCl}_{2}$ and $0.2 \mathrm{mg}$ of the precipitate mixed with $\mathrm{NiO}_{4}$ into tin cups, and the mixture placed into an autosampler for analysis by a Carlo-Erba Elemental Analyzer (CHN EA1110) for combustion to $\mathrm{SO}_{2}$. The clean $\mathrm{SO}_{2}$ was carried by helium to a Thermo Finnigan DELTA plus XL Continuous Flow Stable Isotope Mass Spectrometer for sulfur isotope ratio analysis. Results were corrected to sulfate standards IAEA-SO-5, IAEA-SO-6 and NIST-127 (all $\left.\mathrm{BaSO}_{4}\right)$, and/or IT2 substandard IT2-42 $\left(\mathrm{BaSO}_{4}\right)$. 'IT2' denotes Internal Standards with values calibrated to NIST International Standards. The 1-sigma error for clean standard material is $\pm 0.3 \%$ for sulfur.

$\mathrm{S}(-\mathrm{II})$ and ferrous iron (Fe(II)) were determined photometrically on samples filtered through $0.2 \mu \mathrm{m}$ filters by the methods described by Cline (Cline, 1969) and Stookey (Stookey, 1970), respectively. Analytical error (1-sigma error) is less than $2.5 \%$ for S(-II) assay, and less than $2 \%$ for $\mathrm{Fe}(\mathrm{II})$ assay. Dissolved hydrogen was measured by a headspace equilibration method, as described by Bagnoud et al. (Bagnoud et al., submitted). Briefly, a volume of about $10 \mathrm{~mL}$ of water was recovered in a serum bottle that was previously flushed with $\mathrm{N}_{2}$, at a known final pressure, and contained $\mathrm{HgCl}_{2}$. After sampling, the bottle was incubated horizontally at $37^{\circ} \mathrm{C}$ for at least $24 \mathrm{~h}$ to equilibrate the gas phase with the aqueous phase. The gas phase composition was analyzed using a GC-FID (Varian 450-GC, Agilent, Santa Clara, USA). The dissolved $\mathrm{H}_{2}$ concentration was calculated using the bottle's initial pressure, the bottle volume, the sampled water volume, the incubation temperature and Henry's Law constant for $\mathrm{H}_{2}$. Analytical error (1-sigma error) is less than $5 \%$.

\subsection{Rate calculation}

Simple differential rates $(R)$ of hydrogen and sulfate consumption were assessed with different methods:

(A) First, the rate $R$ of hydrogen or sulfate consumption was obtained simply by calculating the concentration $C$ difference during a time interval $t$ (Eq. (2)):
$R\left[\mu \mathrm{mol} \cdot \mathrm{cm}^{-3} \cdot \mathrm{d}^{-1}\right]=\frac{d C\left[\mu \mathrm{mol} \cdot \mathrm{cm}^{-3}\right]}{d t[d]}$

The rate of sulfate consumption can be also assessed with the same equation by using the increase in sulfide concentration over time.

(B) The rate of hydrogen oxidation was also assessed by comparing the measured $\mathrm{H}_{2}$ concentration profile (which is decreasing with depth) to that predicted using Fick's first law of diffusion (by which the $\mathrm{H}_{2}$ distribution is expected to be uniform as a function of depth). When hydrogen diffuses from the gas phase and is consumed in the aqueous phase, assuming a steady state (diffusion from the gas phase equals bacterial consumption in the aqueous phase), the flux of hydrogen $F$ can be calculated according to Eq. (3):

$F\left[\mu \mathrm{mol} \cdot \mathrm{cm}^{-2} \cdot \mathrm{s}^{-1}\right]=D_{w}\left[\mathrm{~cm}^{2} \cdot \mathrm{s}^{-1}\right] \cdot \frac{d C\left[\mu \mathrm{mol} \cdot \mathrm{cm}^{-3}\right]}{d z[\mathrm{~cm}]}$

in which $D w=5.13 \cdot 10^{-5} \mathrm{~cm}^{2} \cdot \mathrm{s}^{-1}$ and $z$ represent the sample height (Jähne et al., 1987). The volumetric rate of hydrogen consumption $R$ can be calculated by dividing the hydrogen flux by the height (Eq. (4)):

$R\left[\mu \mathrm{mol} \cdot \mathrm{cm}^{-3} \cdot \mathrm{d}^{-1}\right]=\frac{F\left[\mu \mathrm{mol} \cdot \mathrm{cm}^{-2} \cdot \mathrm{d}^{-1}\right]}{\mathrm{dz}[\mathrm{cm}]}$

(C) Additionally, the rate of sulfate reduction was also calculated using the sulfate to bromide concentration ratio. Indeed, because the concentration of sulfate is not uniform in the borehole, we need to compare it to a conservative tracer (bromide) that was injected at the very beginning of the experiment (Fig. 2). If sulfate is not reduced by microorganisms, the ratio between sulfate and bromide should remain constant for the duration of the experiment. Eq. (5) can be used to calculate the theoretical sulfate concentration $\mathrm{Se}$ at time $i$ without any microbiological reduction, based on the initial ratio (at time 0 ) between sulfate and bromide, and the bromide concentration at time $i$ :

$S e_{t=i}[m M]=\frac{C_{t=0}^{S O_{4}}}{C_{t=0}^{B r}} \cdot C_{t=i}^{B r}$

In a second step, the change in concentration of sulfate due to its biological reduction $\mathrm{Sr}$ at time $i$ can be calculated by simply subtracting the actual sulfate concentration $C$ measured at time $i$ to Se, using Eq. (6):

$S r_{t=i}[m M]=S e_{t=i}-C_{t=i}^{S O_{4}}$

Then Eq. (2) can be used for calculating the sulfate reduction rate, using $S r$ as $d C$.

(D) Finally, the rate of sulfate reduction was evaluated by measuring the change in $\delta^{34} \mathrm{~S}-\mathrm{SO}_{4}$. Indeed, sulfate-reducing bacteria will preferentially reduce the lighter $\mathrm{S}$ isotope, resulting in an increase in $\delta^{34} \mathrm{~S}-\mathrm{SO}_{4}$ (Canfield, 2001). First, the ratio between the change in $\delta^{34} \mathrm{~S}-\mathrm{SO}_{4}$ and the change in sulfate concentration over time $R_{f r}$ was determined and calculated using Eq. (7): 
$R_{f r}\left[\% o \cdot m M^{-1}\right]=\frac{d\left(\delta^{34} \mathrm{~S}-\mathrm{SO}_{4}\right)[\% o]}{d C[m M]}$

$R_{f r}$ was determined in laboratory conditions, in bottles where sulfate concentrations were homogenous. This parameter allows us to translate any in situ change in $\delta^{34} \mathrm{~S}-\mathrm{SO}_{4}$ to a change of concentration due to sulfate reduction $\mathrm{Sr}$, using Eq. (8):

$\operatorname{Sr}[m M]=\frac{d\left(\delta^{34} \mathrm{~S}-\mathrm{SO}_{4}\right)[\% 0]}{R_{f r}\left[\% \cdot m M^{-1}\right]}$

Finally, sulfate reduction rate can be calculated with Eq. (2), using $\mathrm{Sr}$ as $d C$.

\section{Results}

\subsection{Variation in anion concentrations}

The concentration of sulfate decreases during the first 276 days of hydrogen injection, then increases until day 330 before dropping again at day 420 (Fig. 4). In contrast, the concentration of chloride is more stable, even though a slight decrease is observed, and the concentration of bromide decreases to near zero (Fig. 4).

\subsection{Repeated sampling}

The results of the repeated sampling experiment are presented in Fig. 5. The position of samples in the water column relative to the tip of the sampling line was determined by dividing the volume of water withdrawn prior to sampling by the surface area of the water-gas interface (i.e., $104 \mathrm{~cm}^{2}$ ). The sulfate concentration decreased and the sulfide concentration increased as the samples approached the water-hydrogen interface. Based on S(-II)

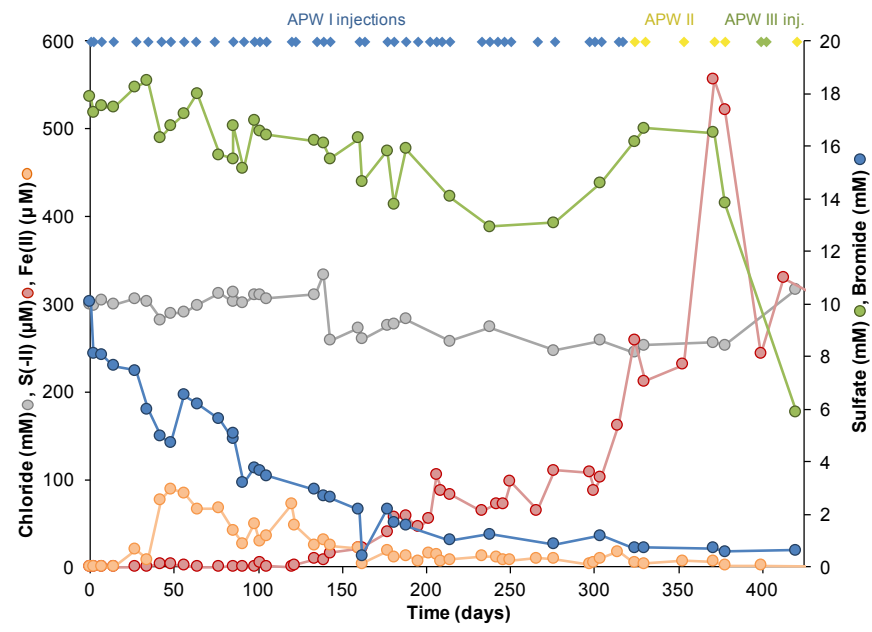

Fig. 4. Change in the concentration of sulfate (in mM, right axis, green circles), chloride (in $\mathrm{mM}$, left axis, grey circles), bromide (in $\mathrm{mM}$, right axis, blue circles), $\mathrm{S}$ (-II) (in $\mu \mathrm{M}$, left axis, red circles) and $\mathrm{Fe}(\mathrm{II})$ (in $\mu \mathrm{M}$, left axis, orange circles) in borehole water over time. Blue, yellow and green diamonds at the top of the plot indicate when APWI, APWII and APWIII (sulfate-free), respectively, were injected after borehole water sampling. The decrease in sulfate concentration observed during the first $\sim 300$ days is mainly caused by borehole water dilution with APW I that has a lower sulfate concentration. Later, after day 324, APW II composition was adapted to initial borehole water composition, with a higher sulfate concentration, explaining why sulfate concentrations increase (Table 1). Bromide concentrations decreased over time because this tracer was only injected at the start of the experiment and was diluted by each APW injection. (For interpretation of the references to colour in this figure legend, the reader is referred to the web version of this article.)

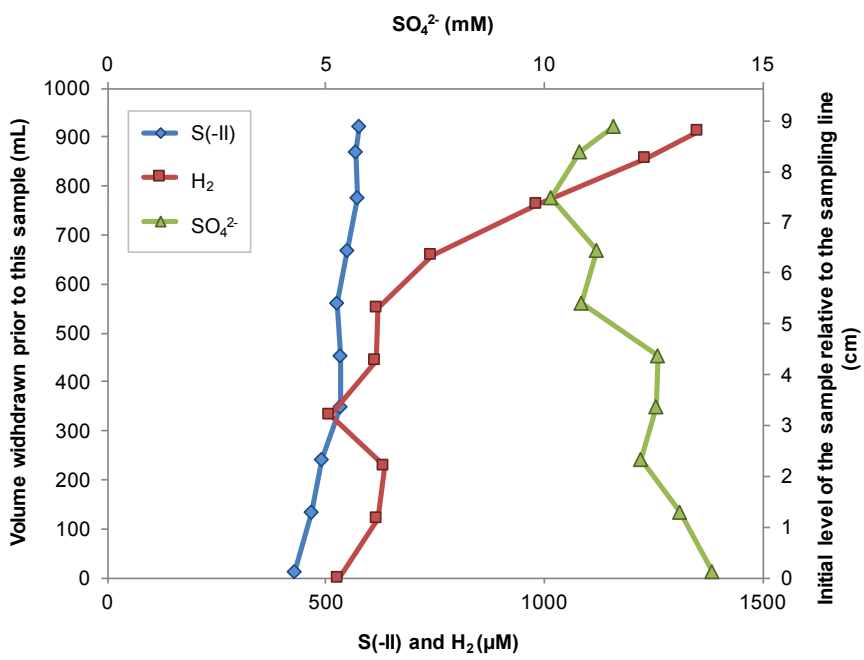

Fig. 5. Sulfate (green triangles, top axis), hydrogen (red squares, bottom axis) and sulfide (blue diamonds, bottom axis)) concentrations from repeated sampling carried out at day 378. For each sample, $\sim 100 \mathrm{~mL}$ of borehole water was withdrawn. As sampling proceeded, the level of the water in the borehole progressively moved closer to the sampling line, allowing collection of water closer to the headspace. (For interpretation of the references to colour in this figure legend, the reader is referred to the web version of this article.)

production and Eq. (2), the rate of sulfate reduction is estimated to be $0.08 \mu \mathrm{mol} \mathrm{cm}{ }^{-3} \mathrm{day}^{-1}$ (Table 2). The concentration of dissolved hydrogen was stable in the first 6 samples, and then steadily increased as the samples approached the gas phase. The rate of hydrogen consumption was estimated for the first six samples, using the change in concentration over time (Eq. (2)), and for the second series of samples, using Fick's first law of diffusion (Eqs. (3) and (4)). Rates are presented in Table 2.

\subsection{Repeated injection}

Results of the repeated injection experiment are shown in Fig. 6. The sulfide concentration steadily increased while the hydrogen concentration fluctuated up and down, depending on whether the sample was recovered immediately or one day after the hydrogen injection (Fig. 6A). Both sulfate and bromide concentrations decreased abruptly two days into the experiment, before slowly increasing. The change in their ratio shows sulfate depletion relative to bromide. ${ }^{34} \mathrm{~S}-\mathrm{SO}_{4}$ appears to be stable over the course of the experiment, except for the last data point, which is almost $2 \%$ greater than the last measurements (Fig. 6B). Hydrogen and sulfate consumption rates, based on hydrogen and sulfide concentration changes over time (Eq. (2)), were calculated to be 1.37 and $0.04 \mu \mathrm{mol} \mathrm{cm}{ }^{-3} \mathrm{day}^{-1}$, respectively (Fig. $6 \mathrm{C}$ and Table 2). Sulfate consumption rates based on sulfate to bromide ratios (Eqs. (5) and (6)) is higher: $0.14 \mu \mathrm{mol} \mathrm{cm}{ }^{-3} \mathrm{day}^{-1}$ (Fig. 6C and Table 2). Finally, the in vitro experiment, during which $1.4 \mathrm{mM}$ of sulfate was reduced and $\delta^{34} \mathrm{~S}-\mathrm{SO}_{4}$ was increased by $0.9 \%$, allowed the estimation of $R_{f r}\left(0.64 \% \mathrm{mM}^{-1}\right)$ (Fig. 7) (Eq. (7)). The rate of sulfate reduction could then be back-calculated from in situ $\delta^{34} \mathrm{~S}-\mathrm{SO}_{4}$ measurement described above and was found to be $0.20 \mu \mathrm{mol} \mathrm{cm}{ }^{-3}$ day $^{-1}$ (Table 2) (Eq. (8)).

\section{Discussion}

\subsection{Temporal variation in the sulfate and hydrogen concentrations}

Assessment of the sulfate reduction and hydrogen oxidation 
Table 2

Summary of all $\mathrm{H}_{2}$ oxidation and sulfate reduction rates calculated in this work.

\begin{tabular}{|c|c|c|c|c|}
\hline & Value & Method & Experiment & Remark \\
\hline \multirow[t]{5}{*}{$\mathrm{H}_{2}$ oxidation rate } & $0.72 \mu \mathrm{mol} \mathrm{cm}^{-3} \mathrm{day}^{-1}$ & $\mathrm{dC} / \mathrm{dt}$ & repeated sampling & Low-end estimate \\
\hline & $3.30 \mu \mathrm{mol} \mathrm{cm}^{-3}$ day $^{-1}$ & $\mathrm{dC} / \mathrm{dt}$ & repeated sampling & High-end estimate \\
\hline & $1.93 \mu \mathrm{mol} \mathrm{cm}{ }^{-3}$ day $^{-1}$ & $\mathrm{dC} / \mathrm{dt}$ & repeated sampling & Used for final estimate \\
\hline & $1.13 \mu \mathrm{mol} \mathrm{cm}{ }^{-3}$ day $^{-1}$ & Fick's first law & repeated sampling & Used for final estimate \\
\hline & $1.37 \mu \mathrm{mol} \mathrm{cm}^{-3} \mathrm{day}^{-1}$ & $\mathrm{dC} / \mathrm{dt}$ & repeated injection & Used for final estimate \\
\hline \multirow[t]{4}{*}{$\mathrm{SO}_{4}^{2-}$ reduction rate } & $0.08 \mu \mathrm{mol} \mathrm{cm}{ }^{-3}$ day $^{-1}$ & $\mathrm{dC} / \mathrm{dt}$ of $\mathrm{S}(-\mathrm{II})$ & repeated sampling & Low-end estimate \\
\hline & $0.04 \mu \mathrm{mol} \mathrm{cm}{ }^{-3}$ day $^{-1}$ & $\mathrm{dC} / \mathrm{dt}$ of $\mathrm{S}(-\mathrm{II})$ & repeated injection & Low-end estimate \\
\hline & $0.14 \mu \mathrm{mol} \mathrm{cm}^{-3} \mathrm{day}^{-1}$ & $\mathrm{SO}_{4}^{2-} / \mathrm{Br}-$ ratio & repeated injection & Used for final estimate \\
\hline & $0.20 \mu \mathrm{mol} \mathrm{cm}^{-3}$ day $^{-1}$ & $\delta^{34} \mathrm{~S}-\mathrm{SO}_{4}$ & repeated injection & Used for final estimate \\
\hline
\end{tabular}
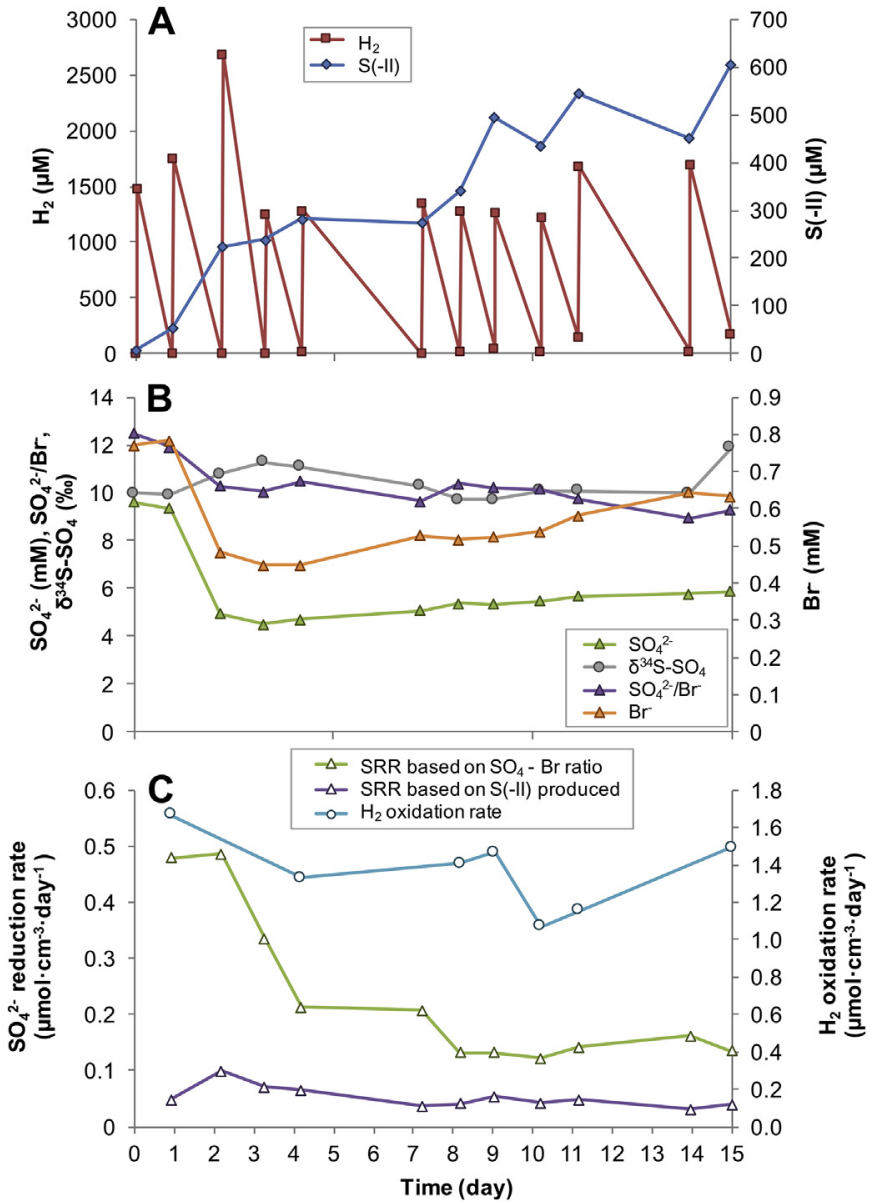

Fig. 6. Chemical evolution of the borehole for the two weeks during which $\mathrm{H}_{2}$ injection was repeated 11 times. (A) Concentration of $\mathrm{H}_{2}$ (red squares, left axis) and $\mathrm{S}$ (-II) (blue diamonds, right axis) used to calculate $\mathrm{H}_{2}$ and $\mathrm{SO}_{4}^{2-}$ consumption rates. (B) Concentration of $\mathrm{SO}_{4}^{2-}$ (green triangles, left axis), $\mathrm{Br}^{-}$(orange triangles, right axis), ratio between $\mathrm{SO}_{4}^{2-}$ and $\mathrm{Br}^{-}$concentrations (purple triangles, left axis), and ${ }^{34} \mathrm{~S}_{-} \mathrm{SO}_{4}$ (grey circles, left axis)). The latter two were used to evaluate the rate of $\mathrm{SO}_{4}^{2-}$ consumption. (C) Sulfate reduction rate (SRR) based on the ratio between $\mathrm{SO}_{4}^{2-}$ and $\mathrm{Br}^{-}$ (green triangles, left axis) or on sulfide production (purple triangles, left axis), and $\mathrm{H}_{2}$ oxidation rate (blue circles, right axis). (For interpretation of the references to colour in this figure legend, the reader is referred to the web version of this article.)

rates in this system is challenging. The diffusion of sulfate from the Opalinus Clay formation into the borehole, and of hydrogen from the borehole into the rock (or through tubing because of leakage) increase the uncertainty of the sulfate and hydrogen mass balances in the borehole as a function of time. The complexity was further increased by the replacement of the large water samples collected for DNA analysis with artificial porewater (APW), with sulfate

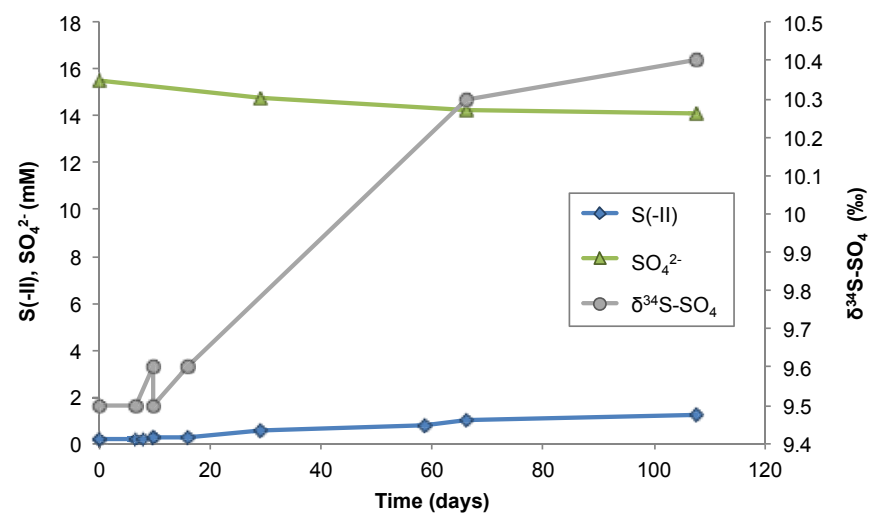

Fig. 7. Evolution of the sulfide concentration (blue diamonds, left axis), sulfate concentration (green triangles, left axis), and $\delta^{34} \mathrm{~S}-\mathrm{SO}_{4}$ (grey circles, right axis) over time in an in vitro batch incubation of borehole water. (For interpretation of the references to colour in this figure legend, the reader is referred to the web version of this article.)

concentrations that did not match the one in the borehole water (Bagnoud et al., submitted). In the first part of the experiment (from day 0 to day 324), the composition of APW (APW I) was based on another borehole in the URL (Table 1; Fig. 2) (Pearson, 2002), where extensive characterization of porewater geochemistry took place. However, the sulfate concentration at that location is lower than that at the BRC-3 borehole (Table 1; Fig. 2). To correct this mismatch between APW and borehole water sulfate concentration, a second APW (APW II) was prepared with a higher sulfate concentration to match the borehole porewater composition. Also, sulfate-free APW III was injected at days 399 and 402 (Table 1; Fig. 2). Another challenge was related to the fact that mixing was limited in the borehole, resulting in significant concentration gradients, particularly for $\mathrm{H}_{2}$ because the only source of $\mathrm{H}_{2}$ was the gas phase at the top of the water column. Additionally, the gas/water interface, where sulfate reduction is likely to take place because the $\mathrm{H}_{2}$ concentration is highest close to the gas phase, was located above the water sampling line, making it difficult to sample this volume directly (Fig. 1).

The concentration of sulfate decreased continuously overtime until day 276 (Fig. 4), which is primarily due to the injection APW with a lower sulfate concentration. The fact that sulfate concentration is lower in the borehole than in APW I (14.7 mM; Table 1) starting day 181 highlights it consumption by another process than dilution in APW I. The latter is clearly sulfate reduction, as shown by hydrogen sulfide accumulation in borehole water (Bagnoud et al., submitted). After day 324, the sulfate concentration tended to increase due to amendment the new APW containing a higher sulfate concentration (APW II, Table 1). The last sulfate measurement is significantly lower, and is explained by borehole water dilution with sulfate-free APW III (Table 1). 


\subsection{Repeated sampling}

The repeated sampling experiment was designed to capture the chemical heterogeneity of the water column caused by hydrogen gas diffusion from the headspace into water. At each sampling, the water level went down, moving the gas/water interface closer to the sampling line (Fig. 3). Because the successive samplings occurred within a short time (about $1 \mathrm{~h}$ ), porewater production in the borehole ( $20 \mathrm{~mL} /$ day) during this time frame is negligible. Using the geometry of the system, we linked the amount of water withdrawn before each sample with the original elevation of the sample relative to the sampling line. The hydraulic conductivity of the clay is obviously much lower than that of the borehole, the tip of the sampling line is oriented perpendicular to the borehole direction, the water flows due to an overpressure of 5.4 bars in the borehole (compared to atmospheric pressure), and the time scale of sampling is too small for significant gravitational flow effects, thus, each sample is composed of water coming from all directions within the borehole, including above and below the tip of the sampling line. This means that a sample recovered after withdrawing $500 \mathrm{~mL}$ will consist approximately of $250 \mathrm{~mL}$ of water originally located above the sampling line, and $250 \mathrm{~mL}$ of water originally located below the sampling line, mixed at a $1: 1$ ratio.

The slope of the concentration of $\mathrm{H}_{2}$ along the water column shows two different behaviors (Fig. 5). The first six samples (farthest from the gas/water interface) exhibit a near-constant hydrogen concentration, around $600 \mu \mathrm{M}$, and indicate that $\mathrm{H}_{2}$ injected previously is still being consumed in this part of the water column. Thus, it is possible to calculate the rate of oxidation of hydrogen by dividing the drop in concentration by the time elapsed using Eq. (2). Depending on whether the initial $\mathrm{H}_{2}$ concentration is taken to be the highest $\mathrm{H}_{2}$ measurement ( $1.35 \mathrm{mM}$ ) or, to correspond to the solubility limit of $\mathrm{H}_{2}$ under in situ conditions (4.24 mM), we obtain a low-end and a high-end estimate of the rate giving a range of $0.72-3.30 \mu \mathrm{mol} \mathrm{cm}{ }^{-3} \mathrm{day}^{-1}$. A better assessment of the initial $\mathrm{H}_{2}$ concentration may be obtained by multiplying the highest measured $\mathrm{H}_{2}$ concentration by two $(2.7 \mathrm{mM})$. This is because this sample, which is closest to the gas phase, has been diluted in a 1:1 ratio with water from deeper in the borehole and containing no $\mathrm{H}_{2}$. Indeed, because $\mathrm{H}_{2}$ was injected through the same sampling line, we assume that its concentration below this point is zero. This value gives an intermediate hydrogen oxidation rate of $1.93 \mu \mathrm{mol} \mathrm{cm}{ }^{-3}$ day $^{-1}$ (Table 2).

The last four water samples (the ones closer to the borehole headspace) exhibit a steady increase in the concentration of $\mathrm{H}_{2}$ as the samples are collected closer to the gas phase (Fig. 5). If diffusion were the only process here, $\mathrm{H}_{2}$ concentration would be homogenous within the water column (like the 6 first samples collected, the ones further from the borehole headspace). This steady change in concentration suggests that $\mathrm{H}_{2}$ diffusion from the gas phase and $\mathrm{H}_{2}$ consumption are competing processes at these locations, and that they reach a steady-state in the top part of the water column. If the repeated sampling had occurred later, the same slope would have been observed for the change in $\mathrm{H}_{2}$ concentration as a function of depth $(d C / d z$ from Eq. (3)), but it would have persisted deeper into the column. We can thus calculate the rate of $\mathrm{H}_{2}$ oxidation by computing the flux of $\mathrm{H}_{2}$ from the gas phase using Fick's first law of diffusion, based on the slope of the four last samples (Eqs. (3) and (4)). For this calculation, we used $\mathrm{H}_{2}$ concentrations for the 7th and 10th samples (1.49 $\mathrm{mM}$ and 2.7, respectively, $d z=2.455 \mathrm{~cm}$ ), both multiplied by two to account for the dilution by $\mathrm{H}_{2}$-free porewater, and a diffusion coefficient of $5.13 \cdot 10^{-5} \mathrm{~cm}^{-2} \mathrm{~s}^{-1}$ (Jähne et al., 1987). The $\mathrm{H}_{2}$ flux was determined to be $2.19 \mu \mathrm{mol} \mathrm{cm}{ }^{-2}$ day $^{-1}$, which corresponds to an $\mathrm{H}_{2}$ oxidation rate of $1.13 \mu \mathrm{mol} \mathrm{cm}{ }^{-3} \mathrm{day}^{-1}$ (Table 2).
In the same experiment, we also calculated the rate of sulfate reduction by dividing the highest concentration of $\mathrm{S}(-\mathrm{II})$ reached during the experiment by the time elapsed since APW injection (Eq. (2)). Unlike for $\mathrm{H}_{2}$, it is not necessary to multiply the $\mathrm{S}(-\mathrm{II})$ concentration by two. Indeed, this compound is produced by microbial activity in the borehole and is thus distributed more homogeneously than $\mathrm{H}_{2}$. Nonetheless, this estimate is likely to underestimate the rate of sulfate reduction because some dilution of sulfide is expected and soluble sulfide only represents a fraction of the total sulfide produced. Indeed, sulfide is expected to precipitate with ferrous iron, as shown by the decreasing Fe(II) concentrations in Fig. 4, which occurred just before sulfide started to build-up. The sulfate reduction rate obtained based on this calculation is $0.08 \mu \mathrm{mol} \mathrm{cm} \mathrm{cm}^{-3} \mathrm{day}^{-1}$ (Table 2).

\subsection{Repeated injection}

The second experiment, involving repeated $\mathrm{H}_{2}$ injection in a borehole where water was mixed by recirculation for 3 days, was designed to capture the rate of sulfate reduction. Every day during 2 weeks, about $150 \mathrm{~mL}$ of water was withdrawn for sampling, moving the gas phase progressively closer to the sampling line. Each sampling was followed by the injection of $1 \mathrm{~L}$ of hydrogen gas, likely homogenizing the $\mathrm{H}_{2}$ concentration in the water above the sampling line (Fig. 6A).

The rate of sulfate reduction was evaluated in three different ways:

(1) Using soluble S(-II) production (Eq. (2)): after 15 days, the rate of sulfate reduction is estimated to be $0.04 \mu \mathrm{mol} \mathrm{cm}{ }^{-3}$ day $^{-1}$ (Fig. 6C; Table 2). As discussed in Section 4.2, soluble $\mathrm{S}(-\mathrm{II})$ does not represent the total S(-II) produced by sulfate reduction, meaning that this calculation is an underestimate.

(2) Comparing sulfate and bromide concentrations (Eqs. (5) and (6)): bromide serves as a conservative tracer. Hence, the steady decrease of the ratio between sulfate and bromide concentrations indicates that sulfate is consumed (Fig. 6B). Sulfate consumption is estimated by calculating the decrease in sulfate relative to a constant sulfate to bromide concentration ratio. After 15 days, the rate of sulfate reduction stabilized. By averaging the 6 last values, we could calculate a rate of $0.14 \pm 0.01 \mu \mathrm{mol} \mathrm{cm}{ }^{-3}$ day $^{-1}$ (Fig. 6C; Table 2).

(3) Using $\delta^{34} \mathrm{~S}-\mathrm{SO}_{4}$ measurements (Eqs. (7) and (8)): porewater was incubated in the laboratory in the presence of hydrogen gas, in a homogenized and closed system in order to estimate the isotopic fractionation of sulfur $\left(\delta^{34} \mathrm{~S}-\mathrm{SO}_{4}\right)$ during sulfate reduction by the borehole microbial community. During the course of the reduction, the change in isotopic composition of sulfur in sulfate was $\Delta_{\text {(final-initial) }}=0.64 \%$. By normalizing the fractionation to the number of moles of sulfate reduced, we obtain a fractionation of $0.64 \%$ per mole sulfate reduced (Fig. 7). Throughout the in situ experiment, $\delta^{34} \mathrm{~S}-\mathrm{SO}_{4}$ doesn't change very much except when the sample obtained is close enough to the borehole headspace to register microbial sulfate reduction and a higher $\delta^{34} \mathrm{~S}-\mathrm{SO}_{4}$ value (Fig. $6 \mathrm{C}$ ). Thus, the change of $1.9 \%$ in $\delta^{34} \mathrm{~S}-\mathrm{SO}_{4}$ corresponds to $2.96 \mathrm{mM}$ of sulfate reduced, which represents a rate of sulfate reduction $0.20 \mu \mathrm{mol} \mathrm{cm}{ }^{-3} \mathrm{day}^{-1}$ (Table 2).

Sulfate reduction rates estimated by the bromide concentration and by $\delta^{34} \mathrm{~S}-\mathrm{SO}_{4}$ are comparable. The fact that these estimates match reasonably well despite originating from two different analytical techniques suggests the robustness of the approach. Moreover, by comparing these two rates with the one obtained 
with S(-II) concentration, we calculate that roughly $75 \%$ of the S(-II) produced precipitates presumably with ferrous iron within a time period corresponding to the experimental duration (15 days), which is consistent with the presence of black particles and $\mathrm{Fe}(\mathrm{II})$ in the borehole water (Fig. 4).

As explained earlier, estimating the rate of hydrogen gas oxidation is also challenging in this system due to potential losses of the gas to the formation and via small leaks through the sampling lines. However, we used the experiment described previously to calculate a hydrogen oxidation rate of $1.37 \pm 0.2 \mu \mathrm{mol} \mathrm{cm} \mathrm{cm}^{-3}$ day $^{-1}$ by averaging the rates obtained from several day-long incubations (excluding the third, the fifth and the tenth incubations on account of inaccurate $\mathrm{H}_{2}$ measurements or too long incubation time at those time points) (Fig. 6A; Table 2), calculated with Eq. (2).

\subsection{Rates of hydrogen and sulfate consumption}

Overall, hydrogen and sulfate consumption rates can be bracketed within a range of values from both experiments (Table 2), excluding low and high-end estimates. The rates of hydrogen oxidation and sulfate reduction were determined to be 1.13-1.93 $\mu \mathrm{mol} \mathrm{cm} \mathrm{cm}^{-3} \mathrm{day}^{-1}$ and $0.14-0.2 \mu \mathrm{mol} \mathrm{cm} \mathrm{cm}^{-3} \mathrm{day}^{-1}$, respectively.

Based on the stoichiometry of hydrogen oxidation coupled to sulfate reduction, given by Eq. (9), each mole of sulfate reduced, requires 4 moles of hydrogen oxidized.

$4 \mathrm{H}_{2}+\mathrm{SO}_{4}^{2-} \leftrightarrow \mathrm{S}^{2-}+4 \mathrm{H}_{2} \mathrm{O}$

However, based on the calculations in this study, the stoichiometry is closer to $1: 8.5$. This result suggests that, in Opalinus Clay, electrons derived from hydrogen oxidation not only reduce sulfate, but also carbon dioxide, via carbon fixation pathways, and probably also ferric iron ( $\mathrm{Fe}(\mathrm{III}))$, through alternate respiratory processes, as presented in by Bagnoud et al. (Bagnoud et al., submitted). In addition, it is likely that some of the apparent consumption of $\mathrm{H}_{2}$ could be attributed to loss via leaks and diffusion into the formation. This ratio between $\mathrm{H}_{2}$ and sulfate consumed is comparable to the one reported by Vinsot et al (Vinsot et al., 2014) in another experiment where $\mathrm{H}_{2}$ consumption in Opalinus Clay was monitored at the Mont Terri URL. In that study, they estimated that $6 \mathrm{H}_{2}$ molecules were oxidized per sulfate reduced. Unfortunately, in the Vinsot et al. study (Vinsot et al., 2014), no information is available on the volumetric rates of $\mathrm{H}_{2}$ and sulfate consumption in the porewater.

Hydrogen and sulfate consumption rates presented here are in the form of zeroth-order kinetics. Even though we are aware that the reality is more complex and these rates should be on the form of first- or second-order kinetics, as they depend on several factor such as $\mathrm{H}_{2}$ and $\mathrm{SO}_{4}^{2-}$ concentrations, the experimental design used here does not allow that assessment. However, hydrogen-utilizing SRB are used to utilize very low $\mathrm{H}_{2}$ concentrations, maintaining conditions favorable for fermentative bacteria (Muyzer and Stams, 2008). This is reflected by the low values of the half-velocity constant $\left(K_{M}\right)$ in the Michaelis-Menten kinetic model for SRB, which are about $1 \mu \mathrm{M}$ for $\mathrm{H}_{2}$ (Kristjansson et al., 1982; Robinson and Tiedje, 1984). This means that the high $\mathrm{H}_{2}$ concentrations used for these experiments only yield rates at saturating $\mathrm{H}_{2}$ concentrations for bacteria, far above $K_{M}$, and thus inform us about the maximum rate $V_{\max }$. This component of the Michaelis-Menten kinetic model is more crucial than $K_{M}$ in the case of safety assessment of nuclear waste disposal, because it better reflects rates of $\mathrm{H}_{2}$ consumption at high $\mathrm{H}_{2}$ concentrations.

\section{Conclusion}

The present work demonstrates that microorganisms, especially sulfate-reducing microorganisms, are able to rapidly oxidize hydrogen in Opalinus Clay. This biological process can beneficial for the safety of geological disposal of nuclear waste. Indeed, hydrogen gas pressure build-up wrought by anoxic corrosion of steel might be reduced by the processes described in this study, resulting in a net improvement of the safety case. On the other hand, sulfatereducing bacteria are known for increasing steel corrosion through their activity, by producing sulfide (Muyzer and Stams, 2008). This implies that a careful repository design is needed to minimize this negative impact. For instance, microbial activity can be promoted in an iron-rich porous medium located somewhere between the canister and the host-rock. This would protect the latter from pressure build-up by consuming hydrogen, and would protect the steel canister by precipitating sulfide with Fe(II), precluding enhanced canister corrosion by sulfide.

Nonetheless, further studies are needed to fully assess the impact of $\mathrm{H}_{2}$ consumption on repositories. The geometry of the repository and its resaturation history are also likely to be important parameters controlling the rate of hydrogen oxidation and the overall amount oxidized. Additionally, the availability of sulfate, the main electron acceptor for hydrogen oxidation, will significantly impact the consumption of $\mathrm{H}_{2}$. The concentration of sulfate in Opalinus Clay porewater ranges between 15 and $20 \mathrm{mM}$ and could be locally depleted due to low hydraulic conductivity of the rock. When sulfate in the porewater becomes depleted and the conversion rate of hydrogen becomes limited by sulfate diffusion into the repository then methanogenesis could further reduce the hydrogen partial pressure in the repository backfill. This process has not been identified in situ and its occurrence remains an open question.

\section{Acknowledgement}

This work was supported by the National Cooperative for the Disposal of Radioactive Waste [order no 8620 and order no. 11,761]. The Swisstopo crew of St-Ursanne is acknowledged for providing excellent working conditions in the Mont Terri underground laboratory. Among these people, Thierry Theurillat is thanked for his precious help for samplings. We also thank Yanick Lettry and Thomas Fierz from Solexperts AG for their help in designing and installing the borehole and surface equipment, and Prof. Andrew Barry and Mohsen Cheraghi from EPFL for the useful discussions regarding the fluidics of the borehole. Finally, we acknowledge the reviewers that provided useful comments that helped improving this manuscript.

\section{References}

ANDRA, 2005. Evaluation of the Feasibility of a Geological Repository in an Argillaceous Formation. Report Series. ANDRA, Châtenay-Malabry, France.

Bagnoud, A., Chourey, K., Hettich, R., de Bruijn, I., Andersson, A.F., Olivier, L.X. Schwyn, B., Bernier-Latmani, R., 2016. Reconstructing a Hydrogen-driven Microbial Metabolic Network in Opalinus Clay Rock (submitted).

Canfield, D.E., 2001. Isotope fractionation by natural populations of sulfate-reducing bacteria. Geochim. Cosmochim. Acta 65, 1117-1124. http://dx.doi.org/10.1016/ S0016-7037(00)00584-6.

Cline, J.D., 1969. Spectrophotometric determination of hydrogen sulfide in natural waters. Limnol. Oceanogr. 14, 454-458. http://dx.doi.org/10.4319/ lo.1969.14.3.0454.

IAEA, 2003. Scientific and Technical Basis for the Geological Disposal of Radioactive Wastes. IAEA Technical Reports Series. International Atomic Energy Agency, New-York

Jähne, B., Heinz, G., Dietrich, W., 1987. Measurement of the diffusion coefficients of sparingly soluble gases in water. J. Geophys. Res. Oceans 92, 10767-10776. http://dx.doi.org/10.1029/JC092iC10p10767.

King, F., 2008. Corrosion of Carbon Steel under Anaerobic Conditions in a Repository for SF and HLW in Opalinus Clay (No. 08-12). Technical Report. National 
Cooperative for the Disposal of Radioactive Waste, Wettingen, Switzerland.

Kristjansson, J.K., Schönheit, P., Thauer, R.K., 1982. Different Ks values for hydrogen of methanogenic bacteria and sulfate reducing bacteria: an explanation for the apparent inhibition of methanogenesis by sulfate. Arch. Microbiol. 131, 278-282. http://dx.doi.org/10.1007/BF00405893.

Le Caër, S., 2011. Water radiolysis: influence of oxide surfaces on $\mathrm{H}_{2}$ production under ionizing radiation. Water 3, 235-253. http://dx.doi.org/10.3390/ w3010235.

Libert, M., Bildstein, O., Esnault, L., Jullien, M., Sellier, R., 2011. Molecular hydrogen: an abundant energy source for bacterial activity in nuclear waste repositories. Phys. Chem. Earth Parts ABC Clays Nat. Eng. Barriers Radioact. Waste Confinement 36, 1616-1623. http://dx.doi.org/10.1016/j.pce.2011.10.010.

Marschall, P., Horseman, S., Gimmi, T., 2005. Characterisation of gas transport properties of the opalinus clay, a potential host rock formation for radioactive waste disposal. Oil Gas. Sci. Technol. 60, 121-139. http://dx.doi.org/10.2516/ ogst:2005008.

Marsh, G.P., Taylor, K.J., 1988. An assessment of carbon steel containers for radioactive waste disposal. Corros. Sci. 28, 289-320. http://dx.doi.org/10.1016/0010938X(88)90111-4.

Muyzer, G., Stams, A.J.M., 2008. The ecology and biotechnology of sulphatereducing bacteria. Nat. Rev. Microbiol. 6, 441-454. http://dx.doi.org/10.1038/ nrmicro1892.

Nagra, 2002. Demonstration of Disposal Feasibility for Spent Fuel, Vitrified Highlevel Waste and Long-lived Intermediate-level Waste (Entsorgungsnachweis). Nagra Technischer Bericht 02-05. Nagra, Wettingen, Switzerland.
Nagra, 2016. An Assessment of the Fate of I/ILW Repository Generated Gas. Nagra Technischer Bericht. Nagra, Wettingen, Switzerland (In prep).

Nealson, K.H., Inagaki, F., Takai, K., 2005. Hydrogen-driven subsurface lithoautotrophic microbial ecosystems (SLiMEs): do they exist and why should we care? Trends Microbiol. 13, 405-410. http://dx.doi.org/10.1016/j.tim.2005.07.010.

Pearson, F.J., 2002. PC Experiment: Recipe for Artificial Pore Water (No. 2002-17) (Mont Terri Technical Note).

Pearson, F.J., Acros, D., Boisson, J.-Y., Fernandez, A.M., Gäbler, H.E., Gaucher, E, Gautschi, A., Griffault, L., Hernan, P., Waber, H.N., 2003. Mont Terri Project: Geochemistry of Water in the Opalinus Clay Formation at the Mont Terri Rock Laboratory. Reports of the FOWG, geological series. Federal office for water and geology FOWG, Bern.

Robinson, J.A., Tiedje, J.M., 1984. Competition between sulfate-reducing and methanogenic bacteria for $\mathrm{H}_{2}$ under resting and growing conditions. Arch. Microbiol. 137, 26-32. http://dx.doi.org/10.1007/BF00425803.

Stookey, L.L., 1970. Ferrozine - a new spectrophotometric reagent for iron. Anal Chem. 42, 779-781. http://dx.doi.org/10.1021/ac60289a016.

Thury, M., Bossart, P., 1999. The Mont Terri rock laboratory, a new internationa research project in a Mesozoic shale formation, in Switzerland. Eng. Geol. 52, 347-359. http://dx.doi.org/10.1016/S0013-7952(99)00015-0.

Vinsot, A., Appelo, C.A.J., Lundy, M., Wechner, S., Lettry, Y., Lerouge, C., Fernández, A.M., Labat, M., Tournassat, C., Canniere, P.D., Schwyn, B. Mckelvie, J., Dewonck, S., Bossart, P., Delay, J., 2014. In situ diffusion test of hydrogen gas in the Opalinus Clay. Geol. Soc. Lond. Spec. Publ. 400, 563-578. http://dx.doi.org/10.1144/SP400.12. 